\title{
Psychological Disorders among Healthcare Workers in Saudi Arabia during COVID-19 Pandemic: A Cross Sectional Study
}

\author{
${ }^{1}$ Marwa Zalat, ${ }^{2}$ Hanan Mosleh, ${ }^{3}$ Khaled Alghamdi, ${ }^{4}$ Adeel Khan, ${ }^{5}$ Ayat Abdallah \\ ${ }^{1}$ Department of Family and Community Medicine, Taibah University, Madinah, Saudi Arabia, \\ Department of Community, Occupational and Environmental Medicine, Zagazig University, Egypt. \\ ${ }^{2}$ Department of Family and Community Medicine, Taibah University, Madinah, Saudi Arabia. And \\ Department of Public Health and Community Medicine, Cairo University, Cairo, Egypt. ${ }^{3}$ Department \\ of pediatrics, Taibah University, Madinah, Saudi Arabia. ${ }^{4}$ Saudi Board Program of Preventive \\ medicine, Makkah, Saudi Arabia. ${ }^{5}$ Department of Family and community medicine, Taibah \\ University, Madinah, Saudi Arabia, and Department of Epidemiology and Preventive medicine, \\ National liver institute, Menoufiya University, Shebin Elkom, Egypt.
}

Submitted :17-08-2020

Revised: $5-10-2020$

Accepted :5-10-2020

\section{Abstract}

Background: Healthcare workers (HCWs) with high risk duties are at a significant risk of psychological distress during the COVID-19 pandemic. Objectives: To estimate the levels of depression, anxiety, and stress among HCWs during COVID-19 pandemic in the Western region in Saudi Arabia, and investigate their associations as being high risk HCWs. Method: A cross-sectional study was conducted using an electronic questionnaire circulated to HCWs via social applications, including socio-demographic information, occupational characteristics, and the validated depression, anxiety, and stress (DASS-21) scale. Results: Around $36.1 \%$ of HCWs suffered from depression and anxiety and $22.9 \%$ suffered from stress. Anxiety median scores were significantly higher among high risk HCWs compared to low risk HCWs $(\mathrm{p}=.002)$. For depression and stress subscales, high risk workers have higher median scores compared to low-risk HCWs but it was not statistically significant. While anxiety was significantly higher among high risk HCWs (45.4\%) compared to low-risk HCWs (17\%) ( $\mathrm{p}=.001)$. Conclusion: High levels of depression, anxiety, and stress are observed among HCWs during the COVID-19 pandemic. HCWs who are working in high risk services have significantly higher anxiety as compared to those who are at low-risk. A psychological crisis intervention plan should be developed and implemented.

Keywords: Psychological disorders, DASS-21, COVID-19, healthcare workers. Corresponding author: Ayat Abdallah E-Mail: ayat_dr2003@yahoo.com

\section{Introduction}

The novel Coronavirus Disease 2019 (COVID-19), caused by Severe Acute Respiratory Syndrome Coronavirus 2 (SARS-CoV-2), rapidly spread from Wuhan City in China to other countries all over the world and resulted in Public Health Emergency of International Concern (PHEIC) declaration. ${ }^{1}$ COVID-19 has estimated global mortality of $3.4 \%$ as reported by the World Health Organization (WHO) with higher mortality rates among older people and those with comorbidities. ${ }^{2}$

Health services in Saudi Arabia have developed enormously over the last two decades, as evidenced by the availability of 
health facilities throughout all parts of the Kingdom. The Ministry of Health (MOH) has a crucial role to play in disease prevention and control, with 32254 physicians and nurses over the kingdom, divided as 14141 physicians (consultant, specialist and resident), and 18113 nurses. ${ }^{3}$ Despite due protection, health care workers (HCWs) had been reported with a higher rate of infection because of their role in the clinical management of patients. HCWs need to ensure adequate infection prevention and control measures in healthcare facilities to reduce the rate of infections. 4

The memories of SARS's high level of infection rate were among HCWs. Besides, approximately half of Middle East Respiratory Syndrome Coronavirus (MERS-CoV), which was first detected in Saudi Arabia in 2012, have occurred in healthcare settings, and $\mathrm{HCW}$ s constitute over one-third of all secondary infections. ${ }^{4}$ Today, escalating numbers of COVID-19 cases and deaths all over the world caused considerable panic and anxiety especially for HCWs which recommend the need for planning palliative care services in these situations. ${ }^{5}$ Furthermore, numerous recent studies in many countries reported higher levels of psychological distress among healthcare workers during the COVID-19 pandemic. ${ }^{6-10}$

Previous research ${ }^{11,12}$ on the psychosocial effects of SARS on hospital staff revealed that besides being significantly complained of fatigue, sleep deprivation, stress; they were also fearful of their own and their family's health and found caring for colleagues as patients were emotionally difficult.

Therefore, the aim of this study was to give insight on the psychological impact of COVID-19 pandemic on HCWs in the Western region in Saudi Arabia with the following objectives; to estimate the level of depression, anxiety and stress among HCWs during COVID-19 pandemic, to investigate the association of depression, anxiety and stress as being a high risk HCWs during the COVID-19 pandemic, and to measure the difference in the levels of depression, anxiety and stress among high-risk and low-risk HCWs. Such information could help to strengthen preparations for potential medical aid team members, provide support for HCWs during such crises especially for those working in high-risk locations and could contribute to alleviating future psychiatric morbidity among HCWs.

\section{Method}

Study design and participants: During the peak time of the COVID-19 pandemic, a cross-sectional study was conducted in the Western region in Saudi Arabia from March 30th to April 30th, 2020.

Population and sampling: The target population was HCWs currently working in the governmental or the private health sectors, KSA. A convenience sampling technique with a snowball element was applied in the study as the questionnaire circulated on social media applications to social groups of HCWs and they further distributed and forwarded it to their colleagues. A sample of $144 \mathrm{HCW}$ s was finally reached.

We defined high risk HCWs for COVID 19 infection as those "HCWs who reported direct patient contact including whether they cared for suspected or documented COVID-19-infected patients". ${ }^{13}$ Low risk healthcare workers are those who are not in direct patient contact.

\section{Data collection tools}

An electronic questionnaire was distributed and circulated via social applications (WhatsApp and Messenger) to the target population of HCWs after explaining the purpose of the study at the

No. 3 July 2021


beginning of the electronic survey. The electronic

Table 1: Socio-Demographic Characteristics of HCWs Distributed by Their Risk of Exposure to Infection in Saudi Arabia ( $n=144)$.

\begin{tabular}{|c|c|c|c|c|}
\hline \multirow[b]{2}{*}{ Variables } & \multicolumn{2}{|c|}{$\begin{array}{c}\text { High risk } \\
\text { workers }\end{array}$} & \multirow[b]{2}{*}{$\begin{array}{c}\text { Total } \\
\mathbf{n}=144 \\
\mathbf{n} \\
\%\end{array}$} & \multirow[b]{2}{*}{$\begin{array}{c}\text { p- } \\
\text { value }\end{array}$} \\
\hline & $\begin{array}{c}\text { No } \\
\mathrm{n}=47 \\
\mathrm{n} \\
\%\end{array}$ & $\begin{array}{c}\text { Yes } \\
\text { n=97 } \\
\text { n } \\
\%\end{array}$ & & \\
\hline \multicolumn{5}{|l|}{ Age group } \\
\hline \multirow{2}{*}{$\leq 40$ years } & 35 & 75 & 110 & \multirow{3}{*}{.706} \\
\hline & 74.5 & 77.3 & 76.4 & \\
\hline$>40$ years & 12 & 22 & 34 & \\
\hline \multicolumn{5}{|l|}{ Gender } \\
\hline \multirow[t]{2}{*}{ Male } & 24 & 66 & 90 & \multirow{4}{*}{$.048^{*}$} \\
\hline & 51.1 & 68.0 & 62.5 & \\
\hline \multirow{2}{*}{ Female } & 23 & 31 & 54 & \\
\hline & 48.9 & 32.0 & 37.5 & \\
\hline \multicolumn{5}{|c|}{ Marital status } \\
\hline \multirow{2}{*}{ Unmarried } & 6 & 10 & 16 & \multirow{4}{*}{.661} \\
\hline & 12.8 & 10.3 & 11.1 & \\
\hline \multirow{2}{*}{ Married } & 41 & 87 & 128 & \\
\hline & 87.2 & 89.7 & 88.9 & \\
\hline \multicolumn{5}{|l|}{ Nationality } \\
\hline Non- & 40 & 82 & 122 & \multirow{4}{*}{.929} \\
\hline Saudi & 85.1 & 84.5 & 84.7 & \\
\hline \multirow{2}{*}{ Saudi } & 7 & 15 & 22 & \\
\hline & 14.9 & 15.5 & 15.3 & \\
\hline \multicolumn{5}{|c|}{ Current position } \\
\hline \multirow{2}{*}{ Physicians } & 34 & 65 & 99 & \multirow{4}{*}{.518} \\
\hline & 72.3 & 67.0 & 68.8 & \\
\hline \multirow{2}{*}{ Nurse } & 13 & 32 & 45 & \\
\hline & 27.7 & 33.0 & 31.1 & \\
\hline
\end{tabular}

$* P<0.05$ is statistically significant

questionnaire consisted of 3 parts: Part 1: Socio-demographic data of the participants: age, gender, marital status, and nationality. Part 2: Occupational characteristics: e.g. profession (physician, nurse ...etc.) and specialty for physicians (consultant, specialist, resident) and whether working with high risk exposure duties during COVID 19 epidemic in
Saudi Arabia or not. Part 3: A validated Depression, Anxiety, and Stress scale (DASS-21) consisting of 21 items, 7 items per each subscale: depression, anxiety, and stress was used in the study. The reliability of DASS-21 showed that it has excellent Cronbach's alpha values of $0.81,0.89$ and 0.78 for the subscales of depressive, anxiety and stress respectively. It was found to have excellent internal consistency, discriminative, concurrent and convergent validities (14). HCWs were asked to score every item on a scale from 0 (never) to 3 (almost always). Sum scores are computed by adding up the scores on the items per subscale and multiplying them by a factor 2 to be equivalent to the longer DASS-42 version. Thus, each of the subscales may range between 0 and 42 . A score of $0-4,5-6,7-10,11-13,14+$ indicates normal, mild, moderate, severe, extremely severe depression respectively. A score of 0-3, 4-5, 6-7, 8-9, 10+ indicates normal, mild, moderate, severe, extremely severe anxiety respectively. A score of 0-7, $8-9,10-12,13-16,17+$ indicates normal, mild, moderate, severe, extremely severe stress respectively. ${ }^{15}$

\section{Data management}

Statistical analysis was done using the Statistical Package for Social Science (SPSS) version 21.0 (SPSS, Chicago, IL, USA). Two types of statistics were done; 1. Descriptive statistics: quantitative data were shown as median (minimummaximum) because continuous data were not normally distributed when examined by the Shapiro-Wilk test, while, qualitative data were expressed as frequency and percentage. 2. Analytical statistics: Chisquared test had been used to measure the association between qualitative variables. For investigating the association between depression, anxiety, and stress and being a high risk healthcare worker, the Chisquared test was used considering the 
normal as the reference group and Fisher

while

exact test was used when appropriate,

Table 2: Distribution of Low-Risk and High-Risk HCWs by Categories of Depression, Anxiety, and Stress.

\begin{tabular}{|c|c|c|c|c|}
\hline DASS subscales & $\begin{array}{c}\text { Low risk HCWs } \\
n=47(32.6 \%)\end{array}$ & $\begin{array}{c}\text { High risk HCWs } \\
\mathrm{n}=97(67.4 \%)\end{array}$ & $\begin{array}{c}\text { Total } \\
n=144(100 \%)\end{array}$ & p-value \\
\hline \multicolumn{5}{|l|}{ Depression } \\
\hline Normal** & $35(74.5)$ & $57(58.8)$ & $92(63.9)$ & \\
\hline Mild & $4(8.5)$ & $23(23.7)$ & $27(18.8)$ & $.034 *$ \\
\hline Moderate & $5(10.6)$ & $10(10.3)$ & $15(10.4)$ & .727 \\
\hline Severe/extremely severe & $3(6.4)$ & $7(7.2)$ & $10(6.9)$ & .740 \\
\hline \multicolumn{5}{|l|}{ Anxiety } \\
\hline Normal** & $39(83.0)$ & $53(54.6)$ & $92(63.9)$ & \\
\hline Mild & $2(4.3)$ & $9(9.3)$ & $11(7.6)$ & .193 \\
\hline Moderate & $5(10.6)$ & $21(21.6)$ & $26(18.1)$ & $.031 *$ \\
\hline Severe/extremely severe & $1(2.1)$ & $14(14.4)$ & $15(10.4)$ & $.008 *$ \\
\hline \multicolumn{5}{|l|}{ Stress } \\
\hline Normal** & $38(80.9)$ & $73(75.3)$ & $111(77.1)$ & \\
\hline Mild & $5(10.6)$ & $13(13.4)$ & $18(12.5)$ & .590 \\
\hline Moderate & $1(2.1)$ & $3(3.1)$ & $4(2.8)$ & 1.00 \\
\hline Severe/extremely severe & $3(6.4)$ & $8(8.2)$ & $11(7.6)$ & .494 \\
\hline
\end{tabular}

${ }^{*} P<.05$ is statistically significant, **Normal is the reference category. (The DASS-21 is a 21-item system that provides independent measures of depression, stress, and anxiety with recommended severity thresholds. Cutoff scores >9, >7, and >14 indicate a positive screen for depression, anxiety, and stress respectively).

Mann-Whitney U test was used to compare median rankings of sets of quantitative data. P-value was considered statistically significant when it was less than 0.05 .

\section{Ethical Considerations}

Ethical approval was obtained from the Scientific Research Ethical Committee of the faculty of Medicine, Taibah University (No \#039-1441\#). The first page of the online questionnaire described the aim of the study and consent was taken on that page. Privacy and confidentiality were assured.

\section{Results}

Table 1 shows that the total number of HCWs was 144, the number of high risk workers $(n=97)$ was nearly double the number $(\mathrm{n}=47)$ of low risk workers $(67.4 \%$ vs. $32.6 \%$ respectively). There was no significant difference in age between HCWs working in high risk services versus those in less risky exposures $\quad(p=0.706)$, however, the percentage of those Table 3: Comparison of The DASS Scores' Rankings for Depression, Anxiety, and Stress Subscales and Total DASS Scores among Low-Risk and HighRisk Workers (Univariate Analysis Using Mann-Whitney U Test).

\begin{tabular}{lccc}
\hline \multirow{2}{*}{$\begin{array}{c}\text { DASS } \\
\text { subscales }\end{array}$} & $\begin{array}{c}\text { Low risk } \\
\text { HCWs }\end{array}$ & $\begin{array}{c}\text { High risk } \\
\text { HCWs }\end{array}$ & \\
\cline { 2 - 3 } & $\begin{array}{c}\text { DASS } \\
\text { median } \\
\text { (Range) }\end{array}$ & $\begin{array}{c}\text { DASS } \\
\text { median } \\
\text { score } \\
\text { Range) }\end{array}$ & $\begin{array}{c}\text { p- } \\
\text { value }\end{array}$ \\
\hline Depression & $4(0-30)$ & $6(0-42)$ & $\mathbf{. 1 9 9}$ \\
\hline Anxiety & $4(0-30)$ & $6(0-40)$ & $\mathbf{. 0 0 2} *$ \\
\hline Stress & $8(0-34)$ & $10(0-42)$ & $\mathbf{. 1 5 8}$ \\
\hline $\begin{array}{l}\text { Total DASS } \\
\text { scale }\end{array}$ & $16(0-94)$ & $22(0-124)$ & $\mathbf{. 0 4 *}$ \\
\hline
\end{tabular}

$* P<.05$ is statistically significant

equal or below 40 years working in highrisky jobs was higher than those above 40 years $(77.3 \%$ vs. $22.7 \%$ respectively) but it 
was not statistically significant. Regarding gender, nearly two- thirds of our participants were males $(62.5 \%)$, and male gender was significantly associated with working in high-risk jobs

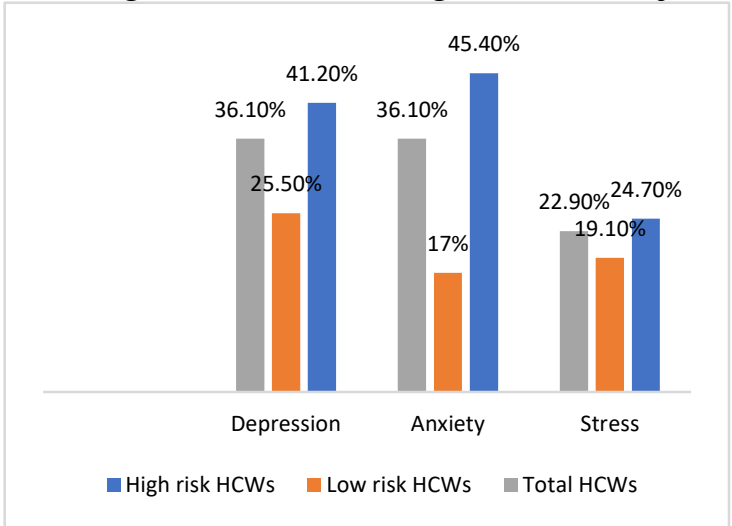

Figure 1: Distribution of Depression, Anxiety, and Stress among High-Risk and Low-Risk HCWs.

than females $(\mathrm{p}=0.048)$. The majority of our participants was married $(88.9 \%)$ and was non-Saudi $(84.7 \%)$. An insignificant association has been found between the current position being a physician or a nurse and being in high risk work $(\mathrm{p}=0.51)$.

Figure 1 illustrates that $36.1 \%$ of HCWs suffered from depression and anxiety, and $22.9 \%$ suffered from stress. Anxiety was significantly $(\mathrm{p}=0.001)$ higher among highrisk HCWs (45.4\%) compared to low-risk HCWs (17\%). For depression and stress, their prevalence among high-risk HCWs was higher compared to low-risk HCWs but this did not reach statistical significance.

Table 2 demonstrates that participants suffering from mild depression constituted $18.8 \%$ of the studied group (8.5\% of lowrisk $\mathrm{HCWs}$ and $23.7 \%$ of high-risk HCWs) and within groups analysis by Chi-squared test showed that the difference between these 2 groups was statistically significant $(\mathrm{p}=0.034)$, while $10.4 \%$ suffered from moderate depression and $6.9 \%$ severe / extremely severe depression. With regard to anxiety, $7.6 \%$ of the group suffered from mild anxiety (4.3\% of low-risk workers and $9.3 \%$ of high-risk workers) and $10.4 \%$ suffered of severe/extremely severe anxiety. Moderate level of anxiety was more frequent among high risk HCWs compared to low-risk HCWs and this was also proven to be statistical significance $(p=.031)$. Similarly, high-risk HCWs showed high frequency of severe/extremely severe anxiety (14.4\%) as compared to low risk HCWs $(2.1 \%)$ and this difference was statistically significant $(\mathrm{P}=.008)$. For mild anxiety, no statistically significant difference was noticed between high-risk HCWs compared to low-risk ones $(\mathrm{p}=.193)$. Concerning stress, $77.1 \%$ of the HCWs were classified as normal while $12.5 \%, 2.8 \%$ and $7.6 \%$ suffered from mild, moderate and severe/extremely severe stress respectively. No statistically significant difference between high- risk HCWs and low-risk ones regarding any level of the stress scale was observed.

Table 3 demonstrates that anxiety median score rankings were higher among highrisk HCWs compared to low-risk ones $(\mathrm{p}=.002)$. For depression and stress subscales, high-risk HCWs had higher median scores compared to low-risk HCWs but the difference was not statistically significant.

\section{Discussion}

The current study demonstrated a vulnerable group susceptible to psychological distress during the current COVID-19 pandemic. The pandemic not only brought the high mortality rate from the viral infection but also psychological distress and mental catastrophe to the rest of the world. ${ }^{16}$ Therefore, the estimation of this psychological impact among HCWs is crucial in guiding policies and interventions to maintain their psychological well-being. ${ }^{17}$ 
The majority of this study participants were below 40 years, married, physicians, which is in agreement with that of a recent single-center Chinese study assessing the psychological impact of COVID-19 pandemic on HCWs in Wuhan. However, the majority of their participants were females which were inconsistent with our participants in which males were slightly higher in number than females. ${ }^{18}$

This study showed significant associations between working in high-risk duties and belonging to the male gender, which could be explained by the nature of work duties and tasks requested from physicians. In our community, female doctors tend to select less stressful specialties which make their exposure to high-risk environment in this study less than the male doctors. ${ }^{19}$

Emerging the new infection of COVID-19 exerts a significant psychological impact on HCWs. The current study showed a high prevalence of depression, anxiety, and stress among HCWs, specifically among the high-risk group. This finding is in agreement with another published data that being the first-hand attendants of the pandemic in the health system and in direct contact with the suspected and confirmed coronavirus cases with greater risk of contracting the virus. As such, more susceptible to psychological distress, and mental health problems relative to low-risk workers. $^{20,21}$

Despite, the suffering of HCWs from longterm psychological consequences that was evident during the previous major outbreak of MERS-CoV that occurred in Saudi Arabia in $2014^{22}$, SARS outbreak, and Ebola virus outbreak ${ }^{23}$, there are other additional factors that can contribute to the occurrence of the current psychological problems. Such novelty of the COVID-19 infection, uncertainty, and unpredictability of its clinical presentation especially many cases were asymptomatic, fast transmission pattern, epidemiological features, the seriousness of public health impact, transparency in declaring the number of infected and died HCWs from coronavirus daily which might lead to pathological grieving among high-risk HCWs. $^{24}$

Furthermore, abrupt changes in HCWS's lives especially for those working in high risk jobs, such as; increase the number of working hours, working load, cancellation of vacations, leaving their families, and hospital isolation might have a major role on occurrence of the psychological problems. $^{25}$

Moderate, and severe, extremely severe level of anxiety was significantly higher than other subscales of the DASS scale, especially among high risk HCWs. Similarly, anxiety was reported as a higher prevalence subscale as documented in other researches on COVID-19 pandemic among HCWs in different countries. ${ }^{6-7,} 17$ Reason for the higher prevalence of anxiety could result from being high risk workers and usually, the HCWs who had high-risk exposure were irritable and anxious from being tested positive after exposure to an asymptomatic case especially with a daily global recording of increasing numbers of HCWs who acquired coronavirus infection from their patients despite taking proper precautions and wearing the proper protective measures. In addition, some HCWs may unfortunately experience avoidance by their family or community owing to fear or stigma of infection, besides lack of psychological support, and mental preparedness before outbreak occurrence.

The present study showed a higher overall DASS-21 median scores among high-risk HCWs compared to low-risk workers with a significant difference for anxiety subscale and total DASS-21 scores. Our findings were higher than those of a recent 
COVID-19 study demonstrating that high risk nurses had significantly lower scores than low risk nurses. ${ }^{16}$ Reasons for our higher scores may include the concurrent application of intensive survey campaigns with massive daily case detection at the time of the study, unremitting stress that could trigger psychological issues of anxiety, fear, and panic attacks. Furthermore, increased work pressure with reduced accessibility to formal psychological support might have a role.

Studies assessing the psychosocial impact of such fatal and highly contagious disease outbreaks on HCWs and the possible intervention programs to be taken should be in priority areas for research in affected countries. In addition, follow-up studies should be conducted to examine the changes over time.

The current study has some limitations. First; a small size convenience sample, while was, at this critical time, the best to fit the process of data collection due to the limited access for face to face interviews with HCWs in hospitals and primary healthcare centers. So, the distribution of data in our sample cannot be generalized of HCWs in other regions. Second; as this study being a cross-sectional study, thus limiting our ability to examine causal relations between the study variables and levels of depression, stress, and anxiety among HCWs. Third; a selection bias exists in our study as the questionnaires were distributed non-randomly via social applications.

\section{Conclusion}

Our study has been conducted during the expected peak time of the COVID-19 pandemic in Saudi Arabia. There is a high prevalence of different levels of depression, anxiety, and stress among healthcare workers, specifically those working in high risk services that are at a higher risk of exposure to infection.

Thus, addressing the mental health issues in healthcare workers is important and essential during such pandemics. Provision of psychological, and community support and access to palliative care to those high risk $\mathrm{HCWs}$ will increase their tolerance to psychological stressors encountered during this critical period.

\section{References}

1. Jianming $\mathrm{G}$, Lianming $\mathrm{L}$, Baoguo $\mathrm{W}$, Xiaoqiang L, Lianrui $\mathrm{G}$, Zhu $\mathrm{T}$, et al. Psychological effects of COVID-19 on hospital staff: a national cross-sectional survey of China mainland. The Lancet Psychiatry, $2020 . \quad$ Available at http://dx.doi.org/10.2139/ssrn. 3550050

2. Adams J, Walls R. Supporting the Health Care Workforce During the COVID-19 Global Epidemic. JAMA (The Journal of the American Medical Association). 2020; 323(15):1439-1440.

doi:10.1001/jama.2020.3972

3. MOH's Media Report on the Occasion of the Saudi National Day 1433H. Available from https://www.moh.gov.sa/en/Ministry/MediaCe nter/Publications/Pages/Publications-2012-0925.aspx. Last accessed March 2020.

4. Elkholy A, Grant R, Assiri A, Elhakim M, Malik M, Van Kerkhove M. MERS-CoV infection among healthcare workers and risk factors for death: Retrospective analysis of all laboratory-confirmed cases reported to WHO from 2012 to 2 June 2018. Journal of Infection and Public Health. 2020; 13(3):418-422. Doi:10.1016/j.jiph.2019.04.011

5. Chen $\mathrm{T}$, Lin $\mathrm{M}$, Chou L, Hwang $\mathrm{S}$. Hospice utilization during the SARS outbreak in Taiwan. BMC Health Services Research. 2006; 4(6):94. Doi:10.1186/1472-6963-6-94.

6. Al-Hanawi M, Mwale M, Alshareef N, Qattan A, Angawi K, Almubark R, Alsharqi O. Psychological Distress Amongst Health Workers and the General Public During the COVID-19 Pandemic in Saudi Arabia. Risk Management Healthcare Policy. 2020; 13: 733-742. 
7. Liu C-Y, Yang Yun-zhi, Zhang X-M, Xu X, Dou Q-L, Zhang W-W, Cheng ASK. The prevalence and influencing factors in anxiety in medical workers fighting COVID-19 in China: a cross-sectional survey. Epidemiology and Infection. 2020; 148 (98): 1-7. https://doi.org/10.1017/S0950268820001107.

8. Al Sulais E, Mosli M, AlAmeel T. The psychological impact of COVID-19 pandemic on physicians in Saudi Arabia: A crosssectional study. The Saudi Journal of Gastroenterology. 2020;10.4103/sjg.SJG_ 174_20. doi:10.4103/sjg.SJG_174_20.

9. Moghanibashi-Mansourieh A. Assessing the anxiety level of Iranian general population during COVID-19 outbreak. Asian Journal of Psychiatry. 2020; 51. https://doi.org/10.1016/j.ajp.2020.102076.

10. Ozamiz-Etxebarria N, Dosil-Santamaria M, Picaza-Gorrochategui M, IdoiagaMondragon N. Niveles de estrés, ansiedady depresión en la primera fase del brote del COVID-19 en una muestra recogida en el norte de España. Cadernos de Saude Publica 2020; 36:e00054020. https://doi.org/10.1590/0102-311X00054020.

11. Maunder R, Hunter J, Vincent L, Bennett J, Peladeau N, Leszcz M, et al. The immediate psychological and occupational impact of the 2003 SARS outbreak in a teaching hospital. Canadian Medical Association or its licensors. 2003; 168(10):1245-1251.

12. McAlona G, Lee A, Cheung V, Cheung C, Tsang K, Sham P, et al. Immediate and Sustained Psychological Impact of an Emerging Infectious Disease Outbreak on Health Care Workers. The Canadian Journal of Psychiatry. 2007, 52(4): 241-247. Doi:10.1177/070674370705200406

13. Nguyen LH, Drew DA, Graham MS, Joshi AD, Guo C, Ma W, Mehta RS, Warner ET, Sikavi DR, Lo C, Kwon S, Song M, Mucci LA, Stampfer MJ, Willett WC, Eliassen AH, Hart JE, Chavarro JE, Rich-Edwards JW, Davies R, Capdevila J, Lee KA, Lochlainn MN, Varsavsky T, Sudre CH, Cardoso MJ, Wolf J, Spector TD, Ourselin S, Steves CJ, Chan AT. Risk of COVID-19 among front-line health-care workers and the general community: a prospective cohort study. Lancet Public Health, 2020 Sep;5(9):e475-e483

14. Coker AO, Coker OO, Sanni D. Psychometric properties of the 21-item Depression Anxiety Stress Scale (DASS-21). African Research Review, 2018; 12 (2). Available

at https://www.ajol.info/index.php/afrrev/article/ view/174532\#: :text=The\%20reliability\%20of $\%$ 20DASS $\% 2 \mathrm{D} 21$, discriminative $\% 2 \mathrm{C} \% 20$ con current $\% 20$ and $\% 20$ convergent $\% 20$ validities.

(Last accessed 11 September 2020)

15. Sinclair S, Siefert C, Slavin-Mulford, J, Stein M, Renna M, Blais M. Psychometric Evaluation and Normative Data for the Depression, Anxiety, and Stress Scales-21 (DASS-21) in a Nonclinical Sample of U.S. Adults. Evaluation \& the health professions, 2011; $35 \quad$ (3):259-79. Doi: $10.1177 / 0163278711424282$

16. Xiao C. A novel approach of consultation on 2019 novel coronavirus (COVID-19) Related psychological and mental problems: structured letter therapy. Psychiatry Investigation. 2020; 17 (2), 175-176.

17. Tan B, Chew N, Lee G, Jing M, Goh Y, Yeo L, et al. Psychological Impact of the COVID-19 Pandemic on Health Care Workers in Singapore. Annals of Internal Medicine. 2020. doi:10.7326/M20-1083

18. Zhu Z, Xu S, Wang H, Liu Z, Wu J, Li G, Miao J, Zhang C, Yang Y, Sun W, Zhu S, Fan Y, Chen Y, Hu J, Liu J, Wang W. COVID-19 in Wuhan: Sociodemographic characteristics and hospital support measures associated with the immediate psychological impact on healthcare workers. EClinicalMedicine. 2020. doi: 10.1016/j.eclinm.2020.100443

19. Mehmood Syed, Al-Binali Ali, and Borleffs Jan. Specialty preferences: Trends and perceptions among Saudi undergraduate medical students. Medical teacher. April 2012, Medical Teacher 34 Suppl 1(Suppl 1):S51-60. DOI: 10.3109/0142159X.2012.656753

20. Rana W, Mukhtar S. Mental health of medical workers in Pakistan during the pandemic COVID-19 outbreaks. Asian Journal of Psychiatry. 2020; 51:102080. Doi:10.1016/j.ajp.2020.102080 
21. Moccia L, Janiri D, Pepe $M$, et al. Affective temperament, attachment style, and the psychological impact of the COVID-19 outbreak: an early report on the Italian general population. Brain Behav Immun. 2020;87:7579. doi:10.1016/j.bbi.2020.04.048.

22. Oboho I, Tomczyk S, Al-Asmari A, Banjar A, Al-Mugti H, Aloraini M, et al. 2014 MERS-CoV outbreak in Jeddah--a link to health care facilities. The England Journal of Medicine. 2015; 372:846-854.

23. Lehmann M, Bruenahl C, Löwe B, Addo M, Schmiedel S, Lohse A, et al. Ebola and psychological stress of health care professionals. Emerging Infectious Disease. 2015; 21:913-914.

24. Mak I, Chu C, Pan P, Yiu M, Chan V. Long-term psychiatric morbidities among SARS survivors. General Hospital Psychiatry. 2009; 31, 318-326.

25. Kang LJ, Li Y, Hu SH, et al. The mental health of medical workers in Wuhan, China dealing with the 2019 novel coronavirus. Lancet Psychiatry. 2020; 7:e14. 